\title{
Capacitor bank controller using artificial neural network with closed-loop system
}

\author{
Widjonarko $^{1}$, Cries Avian ${ }^{2}$, Andi Setiawan ${ }^{3}$, Moch. Rusli ${ }^{4}$, Eka Iskandar ${ }^{5}$ \\ ${ }^{1,2,3}$ Department of Electrical Engineering, Electrical Engineering, Universitas Jember, Indonesia \\ ${ }^{4}$ Department of Electrical Engineering, Control System Engineering, Universitas Brawijaya Malang, Indonesia \\ ${ }^{5}$ Department of Electrical Engineering, Control System Engineering, Institut Teknologi Sepuluh \\ November Surabaya, Indonesia
}

\section{Article Info \\ Article history: \\ Received Jan 27, 2020 \\ Revised Mar 20, 2020 \\ Accepted Apr 6, 2020}

Keywords:

Artificial neural network

Automatic

Capacitor bank

Closed-loop

Power factor correction

\begin{abstract}
The problem of power factor in the industry is critical. This is due to the issue of low power factor that can make the vulnerability of industrial equipment damaged. This problem has been resolved in various ways, one of which is the Automatic Power Factor Correction, with the most popular device called capacitor bank. There are also many methods used, but several methods require certain calculations so the system can adapt to the new plant. In this study, researchers proposed a capacitor bank control system that can adapt to plants with different capacitor values without using any calculations by using an Artificial Neural Network with a closed-loop controller. The system is simulated using Simulink Matlab to know the performance with two testing scenarios. The first is changing the value of the power factor on the system and changing the value of the capacitor power at each bank, the second comparing it with the conventional methods. The results show that the system has been able to adapt to different capacitor power values and has a better performance than the conventional method in power factor oscillation due to the extreme power factor interference.
\end{abstract}

This is an open access article under the CC BY-SA license.



\section{Corresponding Author:}

Widjonarko,

Department of Electrical Engineering,

Universitas Jember,

Jln. Kalimantan 37, Kampus Tegalboto, Jember, East Java, Indonesia.

Email: widjonarko.teknik@unej.ac.id

\section{INTRODUCTION}

In this era, industrial is overgrowing. The rapid growth of the industrial is directly proportional to the increasing need for electrical energy used. The increasing of power needed needs to be encouraged by the maintained power quality. Because it will undoubtedly make the equipment in the industry to become easily damaged cause the quality of the power is terrible [1]. This power quality problem often arises in the industry because the equipment used in the industry on average produces reactive power (inductive load). Therefore, when that equipment active, the power quality decreased [2,3]. With the declining power quality, it will significantly affect the performance of the industry. Both from the economy, such as penalty fees due to low power factor and in terms of investment because some sensitive equipment will be disrupted when the power factor is deficient [3].

For overcoming of quality power problem, a device has emerged. The device is known as Automatic Power Factor Correction (APFC) [4-6]. The principle of this device is to compensate for the reactive power caused by inductive loads by adding capacitive loads [7]. The principle of this device is to compensate for 
the reactive power caused by inductive loads by adding capacitive loads [8]. The types or names of devices used also have many variations [3,9]. Some use the concept of capacitor banks that utilise relays to add capacitive loads to the grid [10-13], dynamic voltage restorer (DVR) [14], static synchronous compensator (STATCOM) [15, 16], and static VAR compensator (SVC) [17, 18].

Meanwhile, when viewed from the automatic control method, several studies develop. However, among the popular ones is to use artificial intelligence controllers such as Fuzzy and ANN. One of them is the Guliyev [19] research, which uses control input references that are current (I) and power factor with $\sin$ I $\theta$ output. Then fuzzy is fed into a closed-loop system to maintain a large VAR (reactive voltage) to connect the number of capacitor banks connected to the system. Likewise, with research conducted by Ragab's [20] that uses PI controls. In this study, researchers rely on Vref (reference voltage when ideal). The system used is also a closed-loop system. This is similar to Moh research [21] that uses Fuzzy logic as a controller. It's just that the input used in control is the power factor angle, and the output is the firing angle of the thyristor. Shuhui's research [6] that uses Artificial Neural Networks to regulate the amount of compensation power. In this control created by Shuhui, the researcher uses two inputs. The first input is the power system (P) and also the nominal bus $(\mathrm{V})$. However, from obtained information, some gaps can be developed. First, the use of power quality compensators by industry using the concept of capacitor banks (relays) is more widely used compared to the concept of DVRs, SVCs or other devices that utilize power electronic components. This is because the capacitor bank is considered to be more economical compared to the power electronics component, which will cause a lengthy repair process and a substantial repair cost if the power electronics component damaged. Secondly, when viewed from several algorithms used (artificial intelligence) [22, 23], some studies still use the concept of power compensation control by calculating how much compensation the system needs to produce a good power factor. That will certainly make the system need to be reset and recalculate if the system is implemented in a different plant, thus making the system not universal or in terms of the computer world known as "plug and play" [24].

Therefore in this study, researchers will take advantage of this opportunity. In this research, the authors will develop the power factor compensates using capacitor bank. But, the system or capacitor bank which developed using a universal system using artificial neural network (ANN) with closed-loop bases. Therefore, with this, the concept of "plug and play" can be achieved. The system will be formed by referring directly to the power factor load. Then by using the closed-loop system, the system will control the capacitor switch so the system can maintain the power factor as good as possible as desired by the user. It could happen cause the ANN will take the switch controller to the right capacitor bank as fast as possible. It is expected that the operation can achieve a faster-repaired power factor so the power quality can be maintained. The fundamental distinguishes the research conducted by Shuhui [6] with the research proposed (which use ANN too), lies in the input and control model used. If Shuhui's study uses the open-loop control model and uses input control references that are the amount of power $(\mathrm{P})$ and nominal bus voltage (V), the research proposed by the author is different. In this study, the author will use a closed-loop control model with input error and delta error, and with the value of the control response as the output. By applying this control model, the system will quickly adapt to the system. In this study, the author will simulate the proposed method using Simulink Matlab. The proposed system will be tested on the system itself made by the author, whose value of the power factor is changed to a specific value. With the change in the value of the power factor at a particular value, the system response can be known its performance.

\section{RESEARCH METHOD}

The power factor can be determined by performing calculations involving two variables. The two variables are real power $(\mathrm{P})$ and apparent power $(\mathrm{S})$. The equation used in (1). In the industrial world, reactive power $(\mathrm{Q})$, is influenced by inductive loads such as motors and transformers. The higher the inductive power connected to the grid, the lower power factor will be. Therefore, to be able to make the power factor value better, the capacitive load must be connected to the system. For more details, the power factor relationship can be seen in Figure 1.

From the equations in (1), it can be seen that the control system needs to do reactive power compensation by connecting capacitive loads into the system to make improvements the power factor. Therefore, the key to improving power factor lies in this way. For realising the power compensation system, in this study, the system block diagram formed. The system block diagram can be seen in Figure 2. In Figure 2, there are several important blocks. First is the block control system. This block contains intelligence control in the form of ANN. Because the method used is a closed-loop system, there are two inputs and one output. The input block is an error which is the difference between the desired setpoint power factor (CPRef) and the current power factor (CPReal) (2), and the input is a delta error (dE) which is the difference from the present error (E0) 
minus the previous error $(\mathrm{E}(\mathrm{t}-1))(3)$. The output of this block is the response value which will be fed into the second block, namely the lagging and leading detection blocks.



Figure 1. Power factor correlation

$$
\text { Power Factor }(P f)=\frac{\text { Real Power }(P)}{\text { Appareant Power }(S)}
$$



Figure 2. Diagram block system

$$
\begin{aligned}
& E=\text { CPRef }- \text { CPReal } \\
& D E=E_{(t-1)}-E_{o}
\end{aligned}
$$

Keep in mind that not all decreased power factor is due to inductive load, but it can also be due to the overload of capacitive power cause of the previous conditions. If the inductive load reduced a lot, but in the previous conditions the amount of capacitive load is still installed a lot too, then power factor down. The decreased power factor causes due to this problem (the high capacitive load which is still connected to the grid), not cause of the inductive load problem. Therefore, if the system is not sensitive to the problems encountered (lagging or leading), the addition of capacitors into the system will only add to the problem (the power factor will decrease more). In this study, to tackle this problem, it will be handled by the second block. The second block is the lagging and leading detection block or power saturation (Figure 3). The function of this block is to do the processing of the control system output to suit the system requirements. This block is detecting the problem causes the power factor decreased as the previous explanation. If the reduced power factor causes a lot of inductive loads (lagging), the system will add the capacitor load to make the power factor good again. But, if the decreased power factor causes a lot of capacitive loads (leading), the system will release the capacitor which switched to the grid. With the voltage and current phase conditions, the second block will work. If lagging occurs (voltage precedes current), the output of the control system will instruct to add the number of relays. But if there is a leading (current precedes the voltage), then the output of the control system will instruct to reduce the number of relays.

Capacitor bank controller using artificial neural network with closed-loop system (Widjonarko) 
The workings of this system can be observed using (4) where Relay is the number of relays that must be installed, OutCs is the control system output, and \pm is the control carried out by the lagging block and leading detection. The system will give a value $(+)$ if there is lagging and the system will provide value (-) if there is leading.

$$
\text { Relay }=\text { Relay } \pm \text { OutCs }
$$

Figure 3 is part of the power saturation block. In this block, the system is built using D Flip-Flop. The input of the D Flip-Flop made by following Figure 3. Figure 3 is an image for detecting alpha signals at a voltage (V) and current (I). For beta and 0 (zero) signals, they will be made according to the circuit pattern in Figure 3. After being arranged according to the circuit pattern above, the output of the D Flip-Flop will be combined using the OR gate.

The next block is Relay and Capacitor. This block is the controllable series of Relay and Capacitors that are ready to be connected to the. While for the last block is the Calculate Power Factor block. The function of this block is to know the change of the response due to the addition of the capacitive load. The total simulation can be seen in Figure 3, which is an implementation of the previous block diagram. In this simulation, the author uses a plant at 3 phase voltage with a power of $1 \mathrm{MW}$ and a frequency of $50 \mathrm{~Hz}$. As for the sensitive load is maintained a resistive load with power value $157600 \mathrm{~W}$. For inductive loads used to generate large amounts of inductive reactive power is an inductor contained in the QL block. The QL block has ten installed inductive loads with each load has a value of 52KVAr. QL block will be controlled so it can generate interference in the form of a decreased power quality at the time of the simulation. Bank of capacitors in the simulation is in the Capacitor Bank block with two blocks. One Capacitor Bank block consists of ten capacitors with varying values for each test to be performed. Among the power capacitor values that will be used are 20KVAr, 50KVAr, $80 \mathrm{KVAr}$. So in this simulation, there are 20 total capacitors (two blocks of capacitor banks). Within this block has been installed a relay that will be controlled by the Control System block in the form of Artificial Neural Network. And the last is the Power Measurement block that is a block used to measure the power factor value for control feedback.

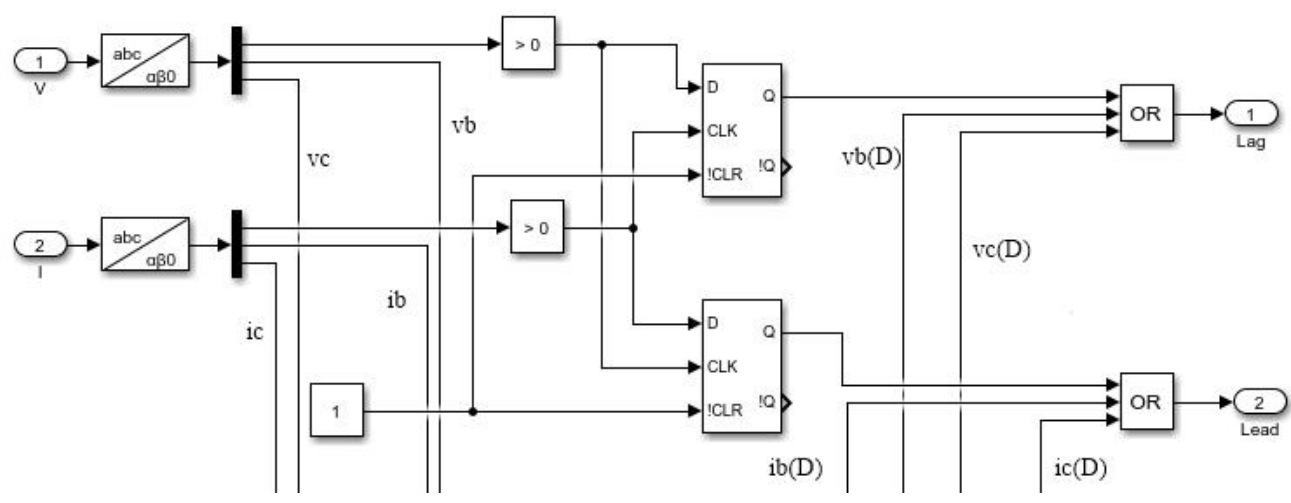

Figure 3. Power saturation block

The ANN structure formed in this study consists of two inputs and one output. The first input is an error, the second input is a delta error, and the output is the response value to the change (represent how many relays must be switch on or switch off). For the structure of the ANN, the structure consists of one layer with ten neurons in each layer. The data used for training is the response data that has been compiled by researchers with closed-loop mechanism data training. The results of the training process have an accuracy of 0.99758, which has exceeded the target of researchers with 0.97 as a standard value. The reason why researchers provided accuracy targets with this value is that the minimum system can follow the trained data from the researcher with response values not far from them. So by ensuring accuracy in the accuracy target range, the trained data performance can be evaluated that is the trained data good or not when the system runs in the simulation process.

For knowing the performance of the proposed system, the test is carried out. The system will be simulated in the Simulink Matlab and will be tested by changed variation of inductive loads connected. With the change of that variation inductive load, it will make power quality of the system changed. 
The changed power quality then will respond by the control system. The author will observe the control system response that the first is the system can follow changes in power quality then fix it or not. And the second is whether the system can maintain the power factor setpoint value that has been set (or at least close to the setpoint value that has been set). Therefore in this study, the test data will be displayed in graphical form to see the comparison between the power factor referenced, the power factor response after repair and the number of relays installed. Besides that, this research will also test by changing the value of bank capacitors to find out that the system can adapt to any capacitor value. The replaced values for each session are 20KVAr, 50KVAr and 80KVAr. The selection of capacitor values on power is based on several capacitor values available on the market. Besides, to testing the system performance by changing the value of the power factor as previous explained, the authors also verify the performance of the proposed system by comparing the performance of the proposed method with the conventional method. The conventional method in question is to add or reduce the number of installed capacitors with a value of 1 . This method is the easiest method to use but still has problems with slow responses [25]. For the total simulation in Simulink Matlab in this research, it can be looked at in Figure 4.

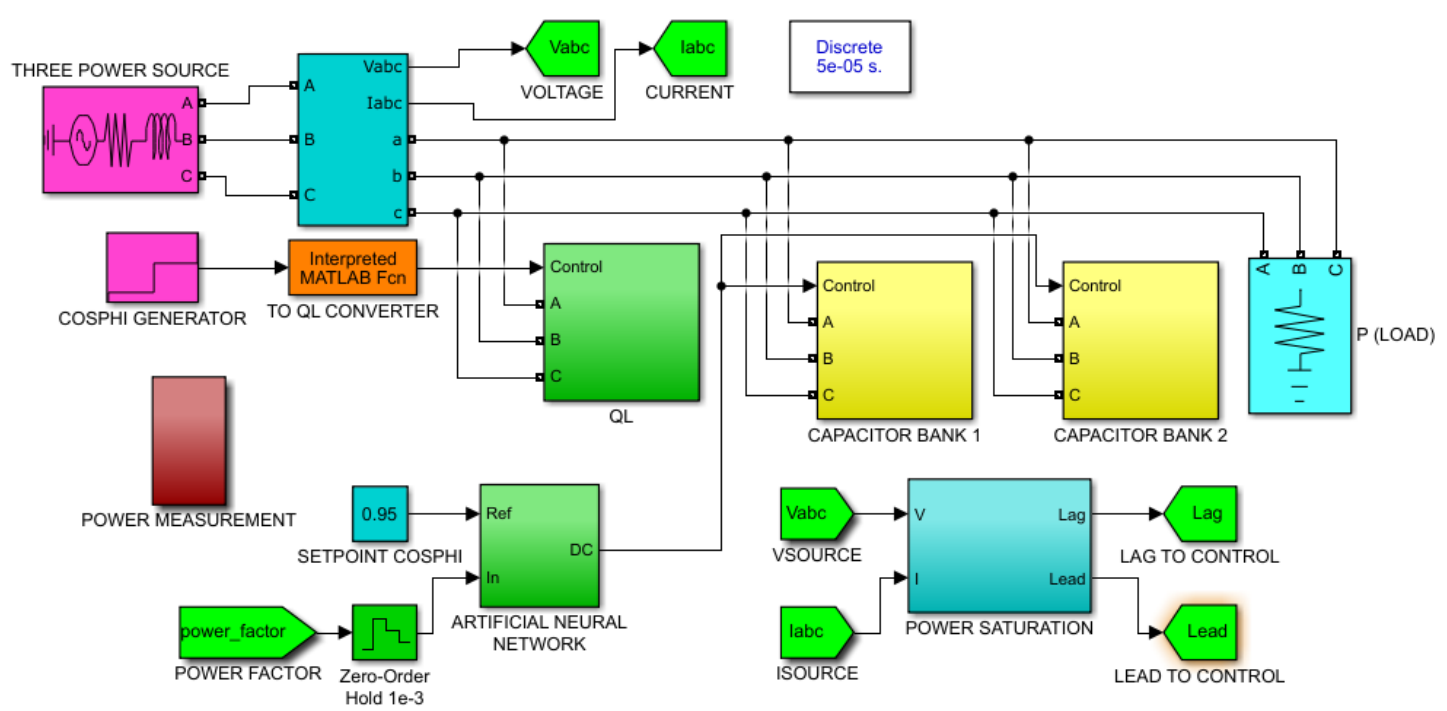

Figure 4. Total simulation power factor correction using an artificial neural network

\section{RESULTS AND DISCUSSION}

In this section, testing is carried out following the test scenarios mentioned in the previous section. By taking some data such as the setpoint used by the user that is the power factor 0.95 , the system response (the value of the actual system power factor), and the number of relay contacts installed, the performance of the system can be seen. For the value of the power factor tested, the author started from $0.5,0.7,0.5,0.8$ and then 0.5. In theory, the higher the power factor value, the smaller the number of inductor values connected, and vice versa. If sorted in each cycle of the power factor value changes, the total value of the connected inductors is 5, 3, 6, 2, and 6. The changing of the power factor or the total installed inductor for tested system performance varies every $0.2 \mathrm{~S}$ according to the mentioned sequence. The results of the system performance testing with this scenario that can be seen in Figures 5-10.

The results show that the proposed system has better performance than conventional techniques. This can be seen in several results produced by conventional methods. In the conventional method, several problems can be seen as happened in Figure 5 (conventional method) where there is a value that falls below 0.6 in seconds $0-0.1 \mathrm{~s}$, while in Figure 6 (ANN) the power factor does not drop below 0.6. Likewise, what happened in Figures 7 and 9, where the power factor value is changing. This is different from what is in Figures 8 and 10 (ANN), which have an oscillation power factor value $(0.6-0.7 \mathrm{~s})$ but not as severe as that of conventional methods. The occurrence of the conventional method problems is due to the responding algorithm that every change of power factor will be responded by increasing or decreasing the number of capacitors by a value of 1 . This can be seen by comparing the responses contained in the Total Capacitor graph section. In conventional methods, the response value that is issued has a smaller value than ANN that can respond to changes with a larger step. Therefore, the system is more stable and faster reach to the setpoint because the value of the right capacitor to compensate for changes in system power factor has been achieved. Therefore the process of the power factor 
correcting becomes longer and more susceptible to interference due to extreme power factor changes such as those contained in the 0.6-0.7 seconds. But this also happens to the proposed system (ANN) where at that time, the power factor also experiences oscillation. As mentioned in the previous explanation that it happen caused by a drastic change in power factor. The power factor changing happens from 0.5 to 0.8 . With this drastic change, the value of the previous capacitor used to compensate the power factor with a value of 0.5 , certainly has an amount more than the system needs to compensate for the power factor at a value of 0.8 . The result is a decrease in power factor due to excessive capacitor load problems. However, with this phenomenon, the system proposed by the author can solve it. The performance proposed method from several systems testing using different capacitor values can adapt and overcome the problem of decreasing power factor that occurs.Also, the proposed method has a better performance in tackling the oscillation problems arise and has closed value to the setpoint value than the conventional method.

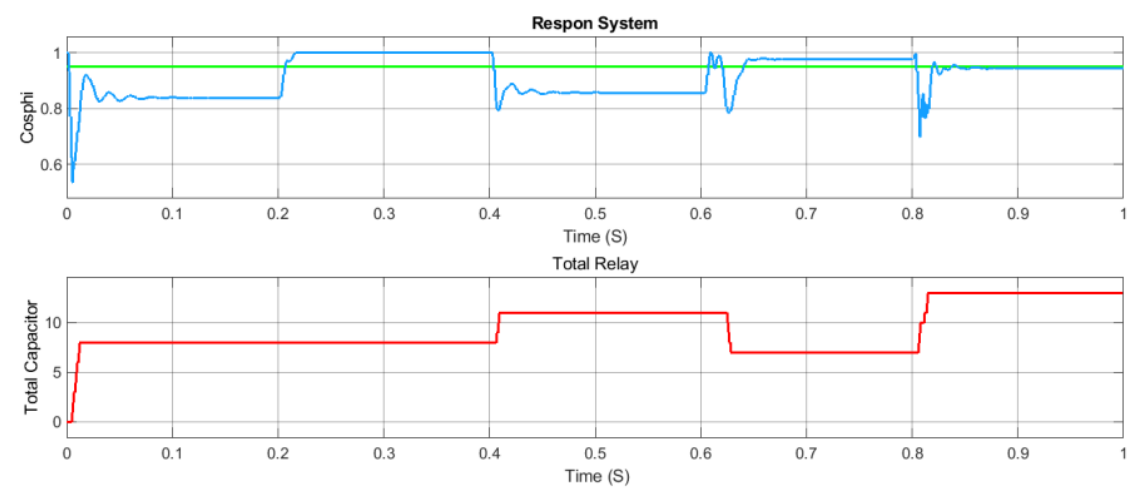

Figure 5. Response system with capacitor power value 20KVAr with conventional method
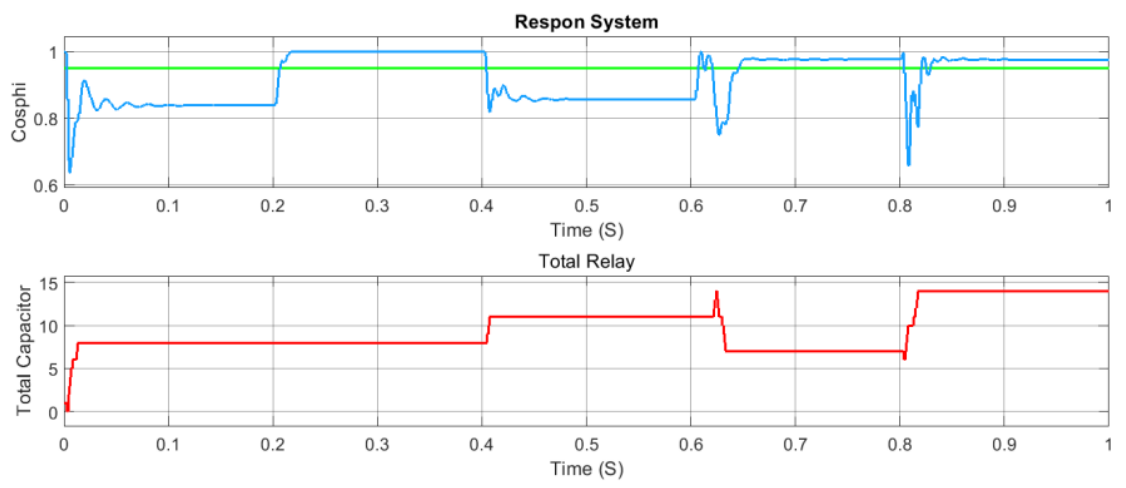

Figure 6. Response system with capacitor power value 20KVAr with ANN

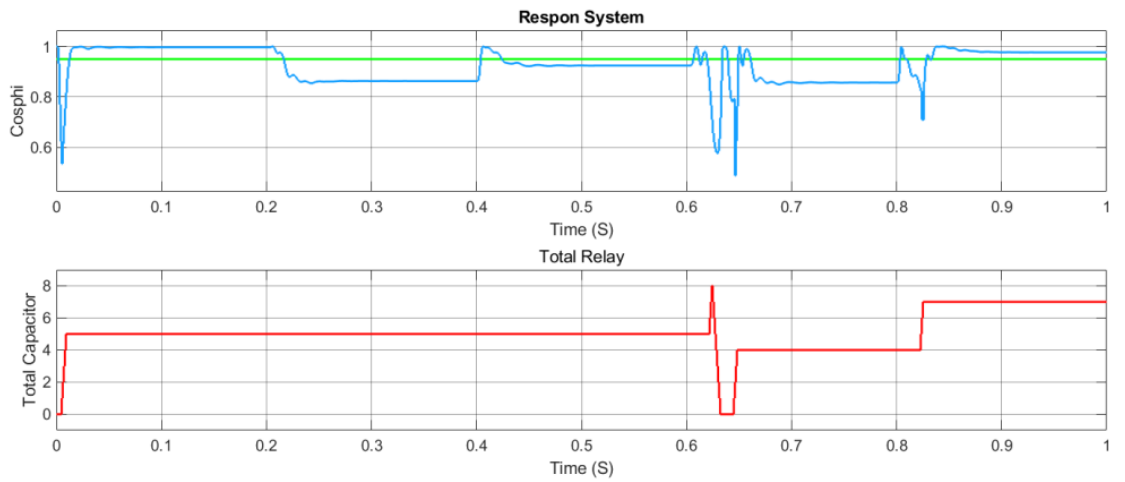

Figure 7. Response system with capacitor power value 50KVAr with conventional method 

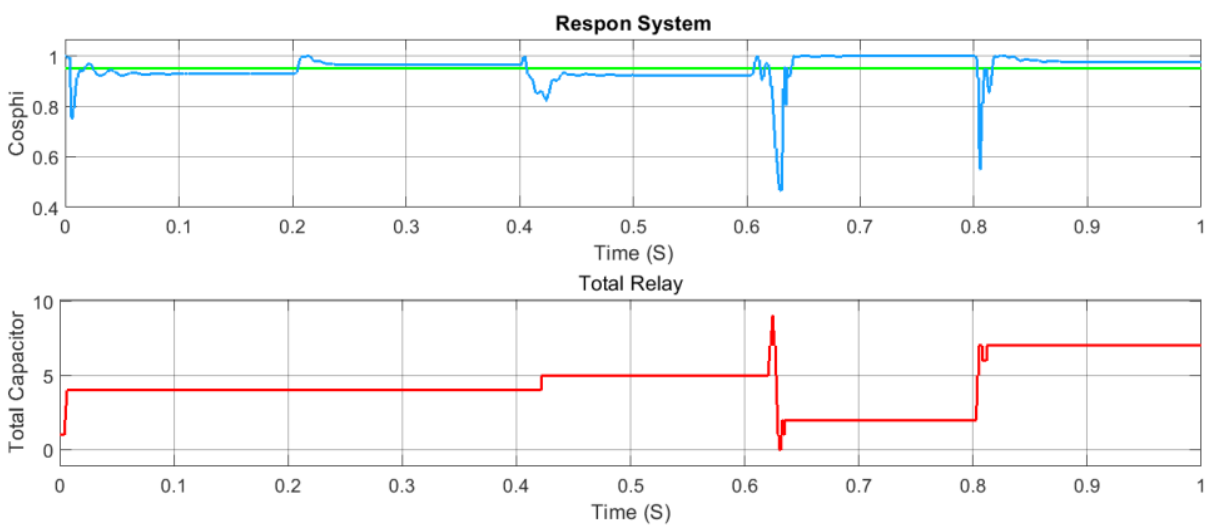

Figure 8. Response system with capacitor power value 50KVAr with ANN
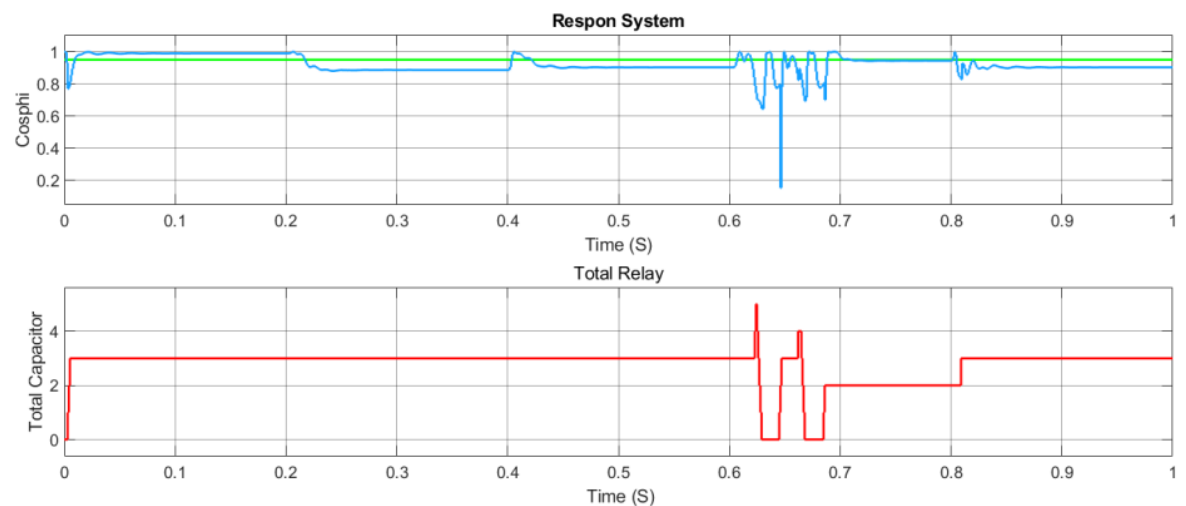

Figure 9. Response system with capacitor power value 80KVAr with conventional method
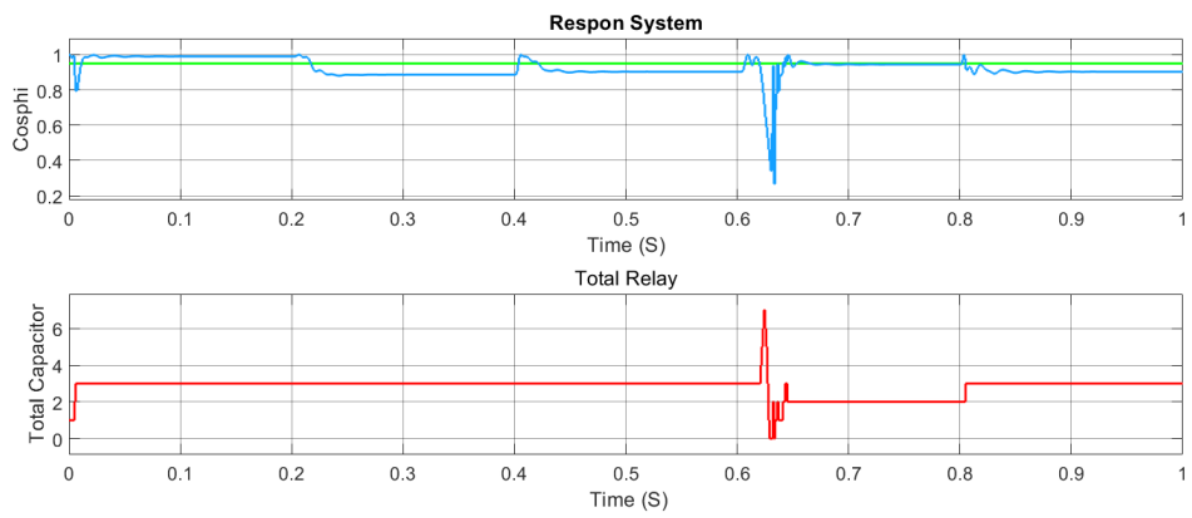

Figure 10. Response system with capacitor power value 80KVAr with ANN

\section{CONCLUSION}

In this paper, an Artificial Neural Network (ANN) has been applied to adjust power factor correction automatically. The results obtained indicate that the implementation of ANN has been able to work on several capacitor power values and have a better performance than the conventional method for tackling the problem, especially in oscillation problem and has closed value to the setpoint value. However, the results obtained suggest that there are still soaring values in testing. This is because in the scenario tested, the power factor used as input has extreme changes. The result is a surge with steep descent because the capacitor load still has a large value that was installed at a previous time. However, despite this phenomenon, the system is still able to adapt to changes in extreme power factors and different capacitor values.

Capacitor bank controller using artificial neural network with closed-loop system (Widjonarko) 


\section{REFERENCES}

[1] K. G. Ravikumar, T. Alghamdi, J. Bugshan, S. Manson, and S. K. Raghupathula, "Complete Power Management System for an Industrial Refinery," 2015 IEEE Petroleum and Chemical Industry Committee Conference (PCIC), Houston, TX, pp. 1-9, 2015.

[2] M. M. Mohamad, A. F. A. El-gawad, and H. S. Ramadan, "Power Factor Improvement for Pumping Stations using Capacitor Banks," International Journal of Emerging Electric Power Systems, vol. 17, no. 5, pp. 597-605, 2016.

[3] A. V. Patil, "'Minimizing Penalty in Industrial Power Consumption by Using APFC unit': A Review," 2019 IEEE International Conference on System, Computation, Automation and Networking (ICSCAN), Pondicherry, India, pp. 1-5, 2019.

[4] V. R. Ananthapadmanabhan, I. Tenison, and S. TN, "Automated Power Factor Improvement Based on Artificial Neural Networks,” 2018 International Conference on Intelligent Autonomous Systems (ICoIAS), Singaporepp, 170-174, 2018.

[5] S. G. Farkoush, A. Wadood, T. Khurshaid, C. Kim, and S. Rhee, "Electrical Power and Energy Systems Minimizing static VAR compensator capacitor size by using SMC and ASRFC controllers in smart grid with connected EV charger," International Journal of Electrical Power and Energy Systems, vol. 107, pp. 656-667, 2019.

[6] S. Li, S. Member, Y. Sun, S. Member, M. Ramezani, and S. Member, "Artificial Neural Networks for Volt/VAR Control of DER Inverters at the Grid Edge," in IEEE Transactions on Smart Grid, vol. 10, no. 5, pp. 5564-5573, 2019.

[7] S. Satsangi and G. B. Kumbhar, "Review on Volt/VAr Optimization and Control in Electric Distribution System," 2016 IEEE 1st International Conference on Power Electronics, Intelligent Control and Energy Systems (ICPEICES), Delhi, pp. 1-6, 2016.

[8] I. S. Shahbudin et al., "FACTS device installation in transmission system using whale optimization algorithm," Bulletin of Electrical Engineering Informatics, vol. 8, no. 1, pp. 30-38, 2019.

[9] M. B. Khan and M. Owais, "Automatic Power Factor Correction Unit," 2016 International Conference on Computing, Electronic and Electrical Engineering (ICE Cube), Quettapp. 283-288, 2016,.

[10] T. P. Pawale, R. Motekar, R. Chakrasali, and S. B. Halbhavi, "An Experimental Design Approach For Power Factor Correction Using PLC," 2017 International Conference On Smart Technologies For Smart Nation (SmartTechCon), Bangalore, pp. 1155-1159, 2017.

[11] H. A. Ismail and G. K. B. Patel, "Automatic Power Factor Correction by Fine Tuning of Graded Capacitors," International Journal of Advance Research, Ideas, and Innovations in Technology, vol. 3, no. 6, pp. 1425-1431, 2017.

[12] Y. Kabir, Y. M. Mohsin, and M. M. Khan, "Automated Power Factor Correction and Energy Monitoring System," 2017 Second International Conference on Electrical, Computer and Communication Technologies (ICECCT), Coimbatore, pp. 1-5, 2017.

[13] S. A. Sadat, "Power Factor Correction of Inductive Loads using PLC," arXiv, pp. 1-8, 2018.

[14] A. F. Ali, W. H. Zayer, and S. S. Shukir, "Fuzzy Logic Controller Based DVR for Power Quality Improvement under Different Power Disturbances with Non-Linear Loads," Iraqi Journal Electrical and Electronic Engineering, vol. 15, no. 2, pp. 51-60, 2019.

[15] M. M. Hashempour and T.-L. Lee, "Integrated Power Factor Correction and Voltage Fluctuation Mitigation of Microgrid Using STATCOM," 2017 IEEE 3rd International Future Energy Electronics Conference and ECCE Asia (IFEEC 2017-ECCE Asia), Kaohsiung, pp. 1215-1219, 2017.

[16] S. Gawish, S. Sharaf, and M. El-Harony, "Experimental Results of a Wind Energy Conversion System with STATCOM Using Fuzzy Logic Controller," Bulletin of Electrical Engineering Informatics, vol. 5, no. 3, pp. 271-283, 2016.

[17] S. G. Farkoush, S.-N. Park, K.-H. Kim, and S.-B. Rhee, "Efficient Power factor improvement with SVC based on the PI controller under Load Fault in the smart grid," International Journal of Applied Engineering Research, vol. 11, no. 1, pp. 96-100, 2016.

[18] P. C. Loureiro, A. M. Variz, L. W. de Oliveira, Â. R. Oliveira, and J. L. R. Pereira, "ANN-Based SVC Tuning for Voltage and Harmonics Control in Microgrids," Journal of Control, Automation and Electrical Systems, vol. 28, no. 1, pp. 114-122, 2017.

[19] A. N. Madhavanunni, J. Baby, S. S. Arya, J. George, J. George, and R. K. D, "Fuzzy Logic Controller for Reactive Power Compensation,” 2015 International Conference on Control Communication \& Computing India (ICCC), Trivandrum, pp. 54-59, 2015.

[20] D. M. Ragab and J. A. Ghaeb, "Enhancing the response of thyristor - controlled reactor using neural network," Internatiomal Transactions on Electrical Energy Systems, vol. 29, no. 12, pp. 1-16, 2019.

[21] M. Moh, M. Aung, and Y. Aung, "A Fuzzy Logic Approach for Improvement of Power Quality Using FCTCR,"American Scientific Research Journal for Engineering, Technology, and Sciences, vol. 26, no. 2, pp. 239-256, 2016.

[22] W. Helmy and M. A. E. Abbas, "Optimal sizing of capacitor-bank types in the low voltage distribution networks using JAYA optimization," 2018 9th International Renewable Energy Congress (IREC), Hammamet, pp. 1-5, 2018.

[23] H. Lee, Y. Park, J. Lee, S. Joung, and C. Park, "Development of advanced Power Factor Computation Algorithm in Harmonics distorted Distribution System," Journal Inst. Electronic Inf. Engineering, vol. 53, no. 7, pp. 121-127, 2016.

[24] Widjonarko, R. Soenoko, S. Wahyudi, and E. Siswanto, "Comparison of intelligence control systems for voltage controlling on small scale compressed air energy storage," Energies, vol. 12, no. 5, pp. 25-28, 2019.

[25] M. M. Uddin, A. Al Mahmud, and N. Islam, "Design \& Implementation of a Microcontroller Based Automatic Power Factor Rectification System for Different Loads," 2019 1st International Conference on Advances in Science, Engineering and Robotics Technology (ICASERT), Dhaka, Bangladesh, pp. 1-6, 2019. 